\title{
Studies on mechanisms of interferon-gamma action in pancreatic cancer using a data-driven and model-based approach
}

\author{
Falko Lange ${ }^{1,2 \dagger}$, Katja Rateitschak ${ }^{1 \dagger}$, Brit Fitzner ${ }^{2}$, Ralf Pöhland ${ }^{3}$, Olaf Wolkenhauer ${ }^{1}$, Robert Jaster ${ }^{2 *}$
}

\begin{abstract}
Background: Interferon-gamma (IFN $\gamma$ ) is a multifunctional cytokine with antifibrotic and antiproliferative efficiency. We previously found that pancreatic stellate cells (PSC), the main effector cells in cancer-associated fibrosis, are targets of IFN $\gamma$ action in the pancreas. Applying a combined experimental and computational approach, we have demonstrated a pivotal role of STAT1 in IFN $\gamma$ signaling in PSC. Using in vivo and in vitro models of pancreatic cancer, we have now studied IFN $\gamma$ effects on the tumor cells themselves. We hypothesize that IFN $\gamma$ inhibits tumor progression through two mechanisms, reduction of fibrogenesis and antiproliferative effects on the tumor cells. To elucidate the molecular action of IFN $\gamma$, we have established a mathematical model of STAT1 activation and combined experimental studies with computer simulations.
\end{abstract}

Results: In BALB/C-nu/nu mice, flank tumors composed of DSL-6A/C1 pancreatic cancer cells and PSC grew faster than pure DSL-6A/C1 cell tumors. IFN $\gamma$ inhibited the growth of both types of tumors to a similar degree. Since the stroma reaction typically reduces the efficiency of therapeutic agents, these data suggested that IFNy may retain its antitumor efficiency in PSC-containing tumors by targeting the stellate cells. Studies with cocultures of DSL-6A/C1 cells and PSC revealed a modest antiproliferative effect of IFN $\gamma$ under serum-free conditions. Immunoblot analysis of STAT1 phosphorylation and confocal microscopy studies on the nuclear translocation of STAT1 in DSL-6A/C1 cells suggested that IFNy-induced activation of the transcription factor was weaker than in PSC. The mathematical model not only reproduced the experimental data, but also underscored the conclusions drawn from the experiments by indicating that a maximum of 1/500 of total STAT1 is located as phosphorylated STAT1 in the nucleus upon IFN $\gamma$ treatment of the tumor cells.

Conclusions: IFN $\gamma$ is equally effective in DSL-6A/C1 tumors with and without stellate cells. While its action in the presence of PSC may be explained by inhibition of fibrogenesis, its efficiency in PSC-free tumors is unlikely to be caused by direct effects on the tumor cells alone but may involve inhibitory effects on local stroma cells as well. To gain further insights, we also plan to apply computer simulations to the analysis of tumor growth in vivo.

\section{Background}

Accumulation of somatic mutations in genes regulating cell growth, survival and differentiation represents a key mechanism in the process of molecular carcinogenesis. Over the last two decades, a large number of oncogenic and anti-oncogenic signal transduction networks have been described and generated considerable interest in

\footnotetext{
* Correspondence: jaster@med.uni-rostock.de

† Contributed equally

2Department of Medicine II, Division of Gastroenterology, Medical Faculty,

University of Rostock, 18057 Rostock, Germany

Full list of author information is available at the end of the article
}

novel approaches aimed at a more systematic understanding of interactions between cellular proteins involved in tumorigenesis. One strategy to meet this goal is the introduction of mathematical models into basic oncological research, taking advantage of recent progress in the field of systems biology [1]. Most importantly, computational models are not only descriptive but may also be used to make predictions that can be tested experimentally. The growing value of systems biology approaches in molecular research has raised hopes that mathematical models may also be applied to clinical oncology. To this day, however, there remains a

\section{Biomed Central}


considerable gap between the level of modeling (mostly related to subcellular processes) and the complexity of tumor growth in vivo.

Here, we describe a pilot study designed to gain molecular insights into the action of an antineoplastic agent in pancreatic cancer (PC), a devastating disease with the worst prognosis of all common human tumors [2,3]. One of the key features of PC is the extended fibrosis, which has been linked to the activation of pancreatic stellate cells (PSC) $[4,5]$. The desmoplastic reaction not only accompanies the disease, but plays an active role in its progression and reduces the efficiency of cytostatic drugs [5-8]. We have previously shown that interferon- $\gamma$ (IFN $\gamma$ ) inhibits fibrogenesis by targeting PSC, and established an ODE (ordinary differential equation)-model of IFN $\gamma$ signaling through STAT1 (signal transducer and activator of transcription) in PSC $[9,10]$. Simulations of the parametric model not only reproduced experimental data well, but also generated predictions regarding the activation of the STAT1 pathway that could be experimentally verified.

Interferons are multifunctional cytokines with antiviral, antiproliferative and immunomodulatory effects [11]. Their antineoplastic action is exploited in the treatment of several human malignancies. Thus, IFNa has been proposed as an active component for the treatment of PC as part of a chemoradiation protocol $[12,13]$. It is currently unknown, however, which cells represent the main targets of IFN action in vivo (PC cells, PSC, other cells?), and what are the molecular determinants of IFN efficiency or inefficiency.

Using a mouse model of heterotopic PC, we initially studied how IFN $\gamma$ affects the growth of tumor cells in the presence and absence of co-injected PSC. Accompanying in vitro studies were performed to determine the growthinhibitory effect of the cytokine on DSL-6A/C1 pancreatic cancer cells and cocultures of tumor cells with PSC. Furthermore, we analyzed IFN $\gamma$ signaling through STAT1 in DSL-6A/C1 cells in a quantitative manner. Subsequently, the signaling data were integrated into a mathematical model of IFN $\gamma$ action in DSL-6A/C1 cells, and linked to the results of our previous studies with stellate cells. Experimental and computational data together suggest that the tumor cells are less responsive to IFN $\gamma$ in that they require higher doses of the cytokine for efficient STAT1 activation and growth inhibition. Interestingly, IFN $\gamma$ nevertheless inhibited the growth of PSC-free tumors in vivo, suggesting the existence of additional cellular targets, such as local stroma cells.

\section{Results}

\section{Effects of IFN $\gamma$ on PC growth in vivo and in vitro}

To test the antitumor and antifibrotic efficiency of IFN $\gamma$ in vivo, we established a mouse model of PC in which the effects of the drug could be directly related to the presence or absence of activated stellate cells. Therefore, $\mathrm{BALB} / \mathrm{c}-n u / n u$ mice (subsequently termed nude mice) were injected with either DSL-6A/C1 pancreatic cancer cells alone (one side), or a mixture of DSL-6A/C1 cells and PSC (opposite flank). Systemic treatment with IFN $\gamma$ was initiated when the faster-growing tumor had reached a size of $6 \mathrm{~mm}$ in one dimension, and continued for 28 days. In accordance with published data [6], tumors grew faster if PSC were co-injected (Figure 1). As indicated by the tumor volumes, IFN $\gamma$-treatment diminished the growth rate of pure DSL-6A/C1 tumors in a non-significant manner (columns 5 and 6). On PSC-containing tumors, IFN $\gamma$ displayed a quantitatively similar, but statistically significant inhibitory effect (columns 7 and 8). Based on these data, we hypothesized that both stellate and cancer cells may be targets of antiproliferative effects of IFN $\gamma$. Expanding previous studies with cultured PSC, we therefore investigated the antiproliferative effects of IFN $\gamma$ in a coculture model of DSL-6A/C1 cells and PSC. In agreement with previous studies [14], PSC stimulated the growth of the tumor cells and vice versa (Figure 2 upper panel), although the effect of stellate cells on DSL-6A/C1 cells just missed statistical significance (column $7 ; \mathrm{p}=0.06$ ). IFN $\gamma$ at $100 \mathrm{ng} / \mathrm{ml}$ significantly inhibited the growth of both types of cells under monoculture and coculture conditions, providing evidence for the hypothesis described above. However, the inhibitory effect of the cytokine on the growth of DSL-6A/C1 cells was lost if the experiment was performed in the presence of serum, or IFN $\gamma$ concentration reduced to $\leq 10 \mathrm{ng} / \mathrm{ml}$ (Figure 2 middle panel). In contrast, we have previously shown that proliferation of PSC was significantly reduced by IFN $\gamma$ even in the presence of FCS, and at a concentration as low as $1 \mathrm{ng} / \mathrm{ml}$ [9]. In order to gain mechanistic insights into the cellular interactions, we analyzed the effect of the coculture on PSC gene expression, focusing on a panel of established PSC-derived mediators. As shown in Figure 2 (lower panel), expression of connective tissue growth factor (CTGF), transforming growth factor- $\beta 1$ (TGF- $\beta 1$ ) and interleukin (IL)-6 (but not IL-1) in PSC was stimulated by cocultured tumor cells. The effects of IFN $\gamma$ on PSC gene expression were altogether mild, with a roughly two-fold up-regulation of IL- $1 \beta$ in cocultures as the most pronounced phenomenon.

\section{STAT1 pathway activation in DSL-6A/C1 cells: biological data and mathematical model}

The differences in the biological responsiveness of PSC and DSL-6A/C1 cells to IFN $\gamma$ prompted us to ask if they could be linked to different efficiencies of the cytokine in the activation of the key transcription factor in IFN $\gamma$ signaling, STAT1. To address the question, we 


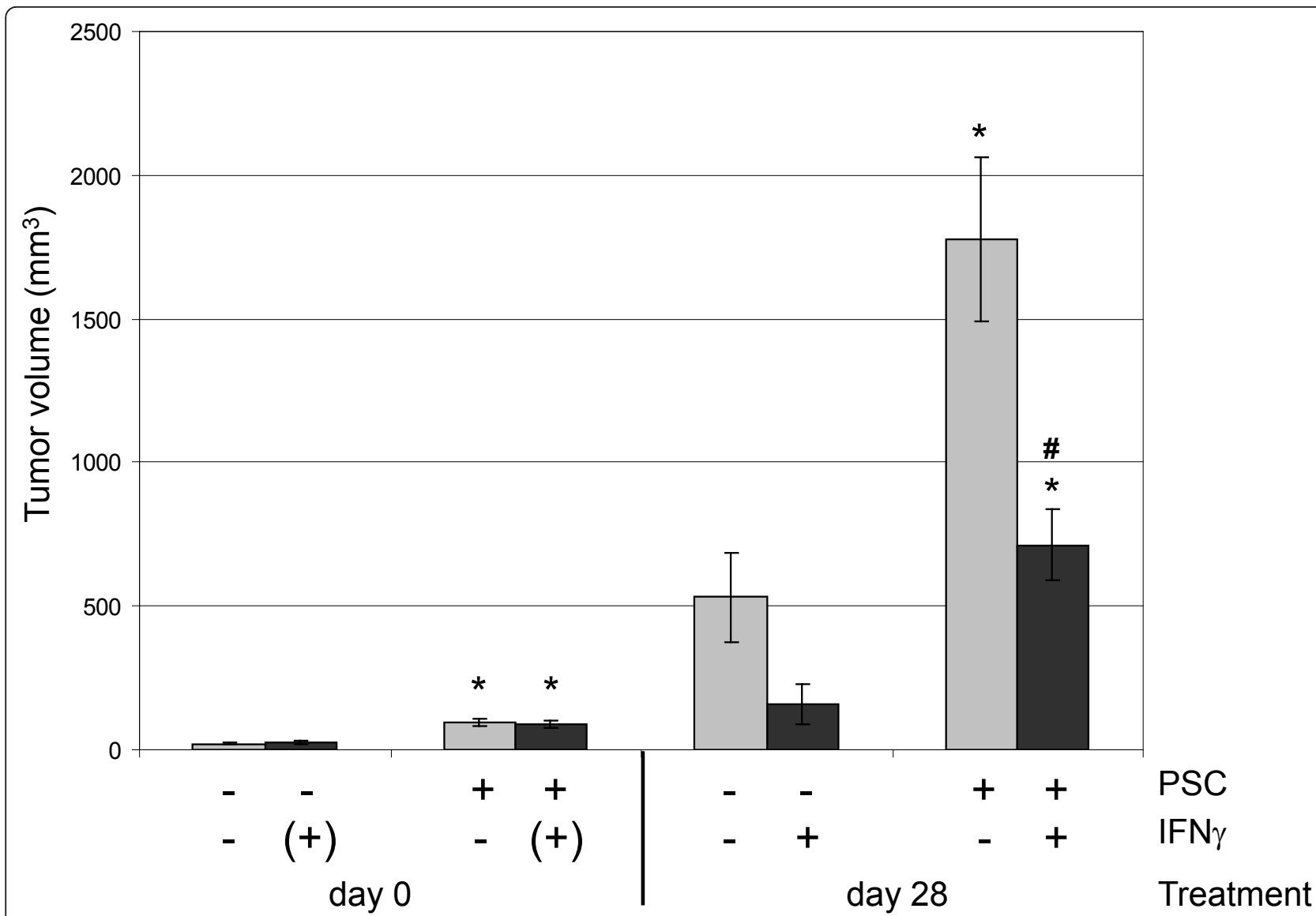

Figure 1 Growth rates of PSC-containing and PSC-free DSL-6A/C1 tumors in nude mice and effects of IFN $\gamma$. Injections of tumor cells, alone or together with PSC, was performed as described in the "Methods" section. Treatment with IFNy (10 $\mu \mathrm{g}$ per day for 4 weeks, $\mathrm{n}=4$ ) started when the faster-growing tumor had reached a size of $6 \mathrm{~mm}$ in one dimension (day 0). Initiation of IFNy treatment is indicated by the symbol $(+)$. Control animals $(n=6)$ received solvent injections only. Indicated are the average values of the tumor volumes \pm SEM. ${ }^{*} p<0.05$ vs. without PSC (paired t-test), \# $\mathrm{p}<0.05$ vs. untreated (unpaired t-test).

combined experimental analysis of STAT1 pathway activation in DSL-6A/C1 cells with computer simulations, taking advantage of a previously established mathematical model of STAT1 signaling in PSC [10]. The reaction network used for computational analysis (Figure 3) contained slight modifications of the previous one [10], which are specified in the figure legend. Subsequently, the network was translated into a system of ODEs, describing temporal changes of the network components as a function of interactions and transport processes. The parameters of the model include reaction constants, delay times and the total receptor concentration. Parameter estimation was done by global optimization from protein and mRNA time series for two different concentrations of IFN $\gamma$ (10 and $100 \mathrm{ng} / \mathrm{ml}$ ). The ODEs and the optimized parameter values are provided in the Additional files 1 and 2 .

As shown in Figure 4 IFN $\gamma$ at the high dose of $100 \mathrm{ng} / \mathrm{ml}$ rapidly induced tyrosine phosphorylation of STAT1. Both, a conventional visualization of the experimental data and the application of the mathematical model concordantly suggested that the increase of phospho-STAT1 happened in two phases: An initial phase of rapid phosphorylation was followed by a second phase characterized by a slow but long-lasting further increase of phospho-STAT1 (Figure 5 upper left diagram). This second phase corresponded to a rise of STAT1 protein levels (upper middle diagram). Increased levels of phospho-STAT1 and STAT1 protein were synchronously detectable in the cytosolic and nuclear cell fraction (middle and lower row, respectively), and well reproduced by the mathematical model. Accordingly, the STAT1 target gene suppressor of cytokine signaling (SOCS1) also displayed a biphasic pattern of enhanced expression (middle row, right diagram).

A quantitative analysis of confocal microscopy data (see Figure 6 for a typical example) and computational simulation together (Figure 5 upper row, right diagram) revealed the surprising finding that IFN $\gamma$-induced phosphorylation of STAT1 left the ratio of nuclear to cytoplasmic STAT1 almost unchanged. We therefore hypothesize that only a small fraction of cytoplasmic 

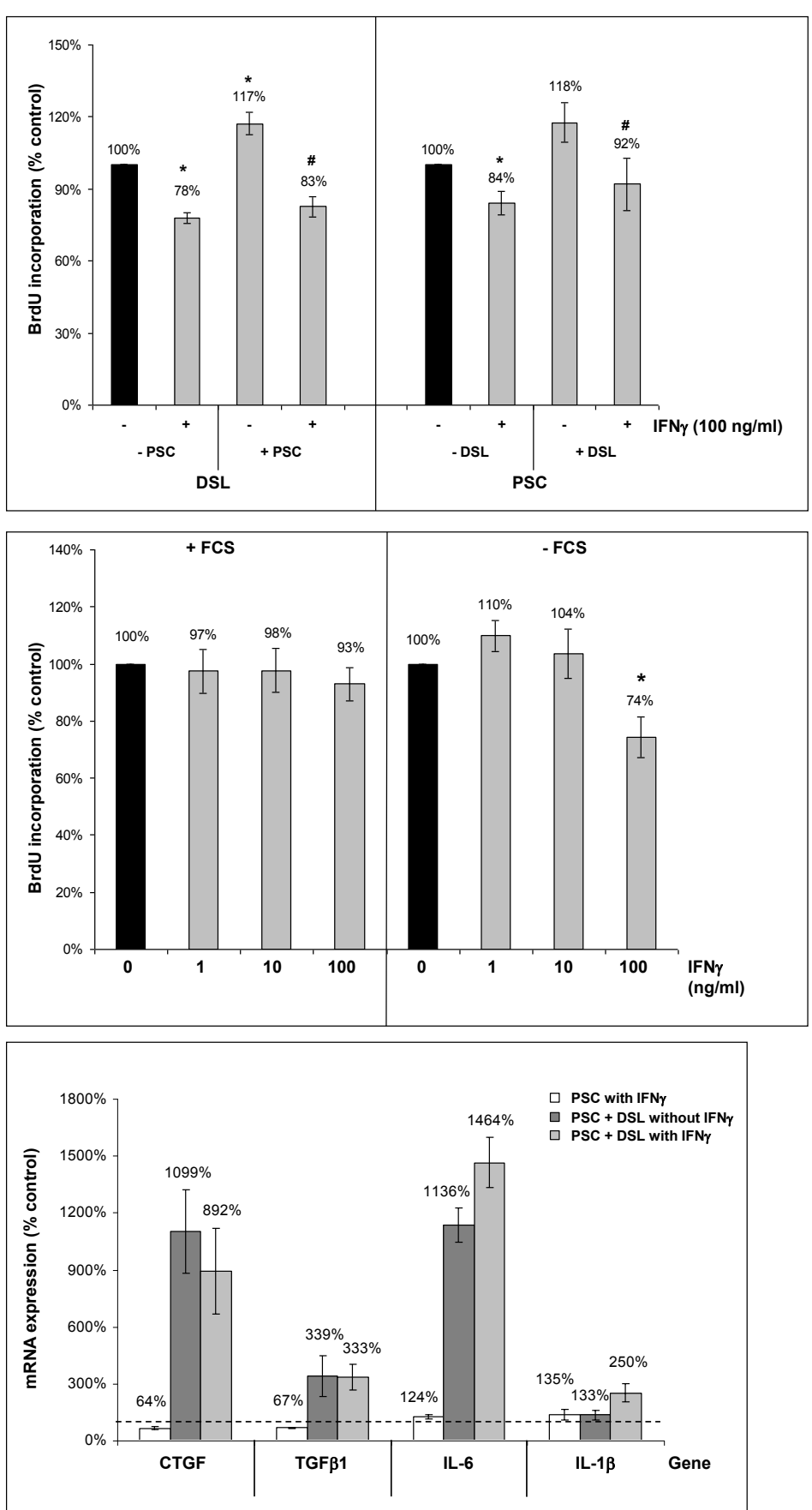

Figure 2 Effects of IFN $\gamma$ on the DNA synthesis and gene expression. Upper panel: DSL-6A/C1 cells and PSC were either cultured alone (columns 1, 2, 5 and 6) or together (columns 3, 4, 7 and 8) in transwell plates. After IFN $\gamma$ treatment for $48 \mathrm{~h}$ under serum-free conditions as indicated, proliferation of DSL-6A/C1 cells (columns 1-4) and PSC (columns 5-8) was assessed with the BrdU incorporation assay. One hundred percent cell proliferation corresponds to DSL-6A/C1 cells or PSC cultured alone and without IFN $\gamma$. Data from 12 separate cultures were used to calculate mean values and SEM. * $p<0.05$ vs. untreated monocultures, \# $p<0.05$ versus untreated cocultures (Wilcoxon's rank sum test). Middle panel: DSL-6A/C1 cells were cultured with or without FCS and IFN $\gamma$ as indicated for $24 \mathrm{~h}$, before DNA synthesis was assessed with the BrdU incorporation assay. One hundred percent BrdU incorporation corresponds to controls cultured without IFN $\gamma$. Data are presented as mean \pm SEM ( $n=6$ separate cultures); ${ }^{*} p<0.05$ vs. control cultures (Wilcoxon's rank sum test). Lower panel: Monocultures of PSC and cocultures of PSC with DSL-6A/C1 cells were treated with IFN $\gamma$ at $100 \mathrm{ng} / \mathrm{ml}$ for $24 \mathrm{~h}$. The mRNA expression of CTGF, TGF- $\beta$ 1, IL-6, IL-1 $\beta$ and the housekeeping gene HPRT in PSC was analyzed by real-time PCR, and relative amounts of target mRNA were calculated as described in the "Methods" section. One hundred percent mRNA expression of each gene (dotted line) corresponds to PSC monocultures grown without IFN . Data of 3 independent experiments (with triplicate samples) were used to calculate mean values and SEM. 


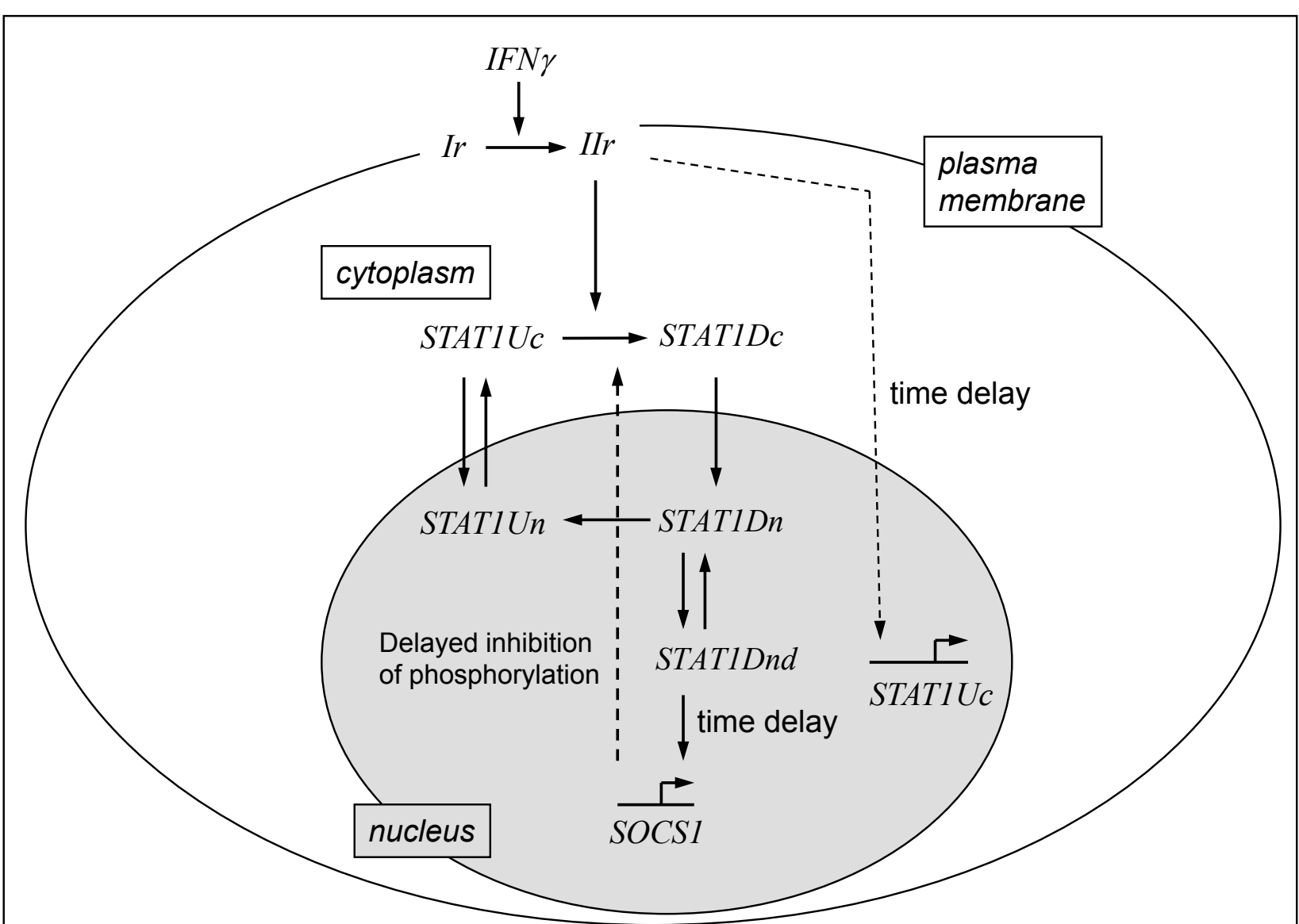

Figure 3 Reaction network of the IFN $\gamma$ stimulated STAT1 signaling pathway. The network shows key reactions of the pathway, which are translated into a mathematical model. IFN $\gamma$ activates the receptor Ir. To keep the model simple, Janus kinases are not considered separately but as part of the active receptor complex IIr only. Ir phosphorylates unphosphorylated cytosolic STAT1 (STAT1Uc), followed by rapid formation of homodimers (STAT1DC). STAT1Dc translocates into the nucleus (STAT1Dn) and induces the transcription of specific target genes by binding to the DNA (STAT1Dnd). When dimerized nuclear STAT1 is not bound to the DNA, dimers may dissociate, followed by protein dephosphorylation and nuclear export of the resulting STAT1Un [27]. STAT1Uc can also shuttle into the nucleus [32]. The network considers SOCS1 as a potential negative feedback regulator inhibiting the phosphorylation of STAT1Uc [28,29] and STAT1 itself as target genes of IFN $\gamma$-activated signaling [10]. The annotation time delay refers to temporal differences between IFNy action at the receptor level and consecutive steps. The level of phosphorylated STAT1 did not decrease despite induction of SOCS1 expression (Fig. 5). This observation suggests that the negative feedback could be effective at late times ( $\geq 180 \mathrm{~min}$ ) only, where it could reduce the slope of the late increase of phosphorylated STAT1. In comparison to the network previously established for stellate cells [10], only two reactions were changed: Since the experimental data showed no decrease of STAT1 phosphorylation, IFN $\boldsymbol{\gamma}$ degradation and receptor deactivation were neglected.

STAT1 was activated, and translocated to the nucleus, after IFN $\gamma$ stimulation. Direct evidence in support of this hypothesis comes from parameter estimation of the mathematical model: According to these results a relative concentration of $1 / 500$ of total STAT1 is an upper boundary for the concentration of phosphorylated STAT1 in the nucleus. This is presented in detail in the Additional file 3.

We also tested the effects of a lower dose of IFN $\gamma$, $10 \mathrm{ng} / \mathrm{ml}$, on STAT1 activation (Figure 7). Both, visualization of experimental data and computational simulations of the mathematical model showed that dose reduction resulted in a slower rise of phospho-STAT1 levels (upper panel), while the enhanced expression of STAT1 protein at later time points after IFN $\gamma$ application was retained (lower panel). At $1 \mathrm{ng} / \mathrm{ml}$, IFN $\gamma$ did not activate STAT1 at all (data not shown). Together, these results suggest that the antiproliferative effect of IFN $\gamma$ in DSL-6A/C1 cells is closely related to the activation of STAT1.

\section{Discussion}

Integrating the design of experiments with mathematical modeling is considered a promising approach to unravel the molecular complexity of tumors [1]. Although computational models may be applied to various fields of cancer research, an improved mechanistic understanding 


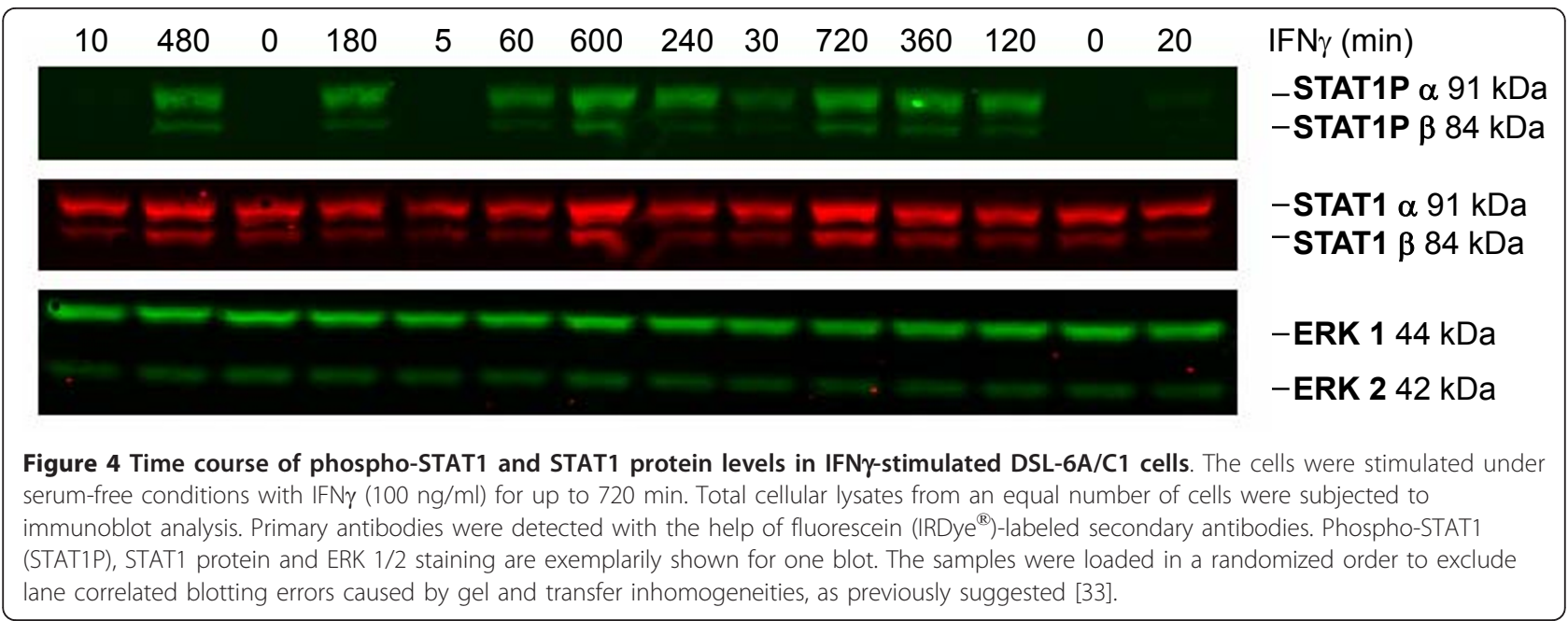

of relevant molecular processes represents a key goal, at least at the current stage. Here, we have analyzed the biological and molecular effects of IFN $\gamma$ in rat pancreatic cancer cells, using a combined experimental and computational approach. Our studies were motivated by the following considerations:

Interferons are of clinical interest in the treatment of pancreatic cancer $[12,13]$. Moreover, they display antifibrotic effects in different tissues $[9,15,16]$, suggesting that they may enhance direct antitumor action by inhibiting pancreatic fibrosis; a progression factor of the disease. We have previously shown that pancreatic stellate cells, the main effector cells in fibrosis, are highly susceptible to IFN $\gamma$ treatment [9], and developed a mathematical model of IFN $\gamma$ signaling through STAT1 [10], the principal transcription factor in the mediation of IFN $\gamma$ effects $[17,18]$. By expanding experimental and modeling efforts to tumor cells, we expected new insights regarding the relative sensitivity of both cell types to the drug.

In contrast to stellate cells $[9,19]$, DSL-6A/C1 cells did not respond to IFN $\gamma$ by diminished cell proliferation as long as they were cultured in the presence of serum. A reduced rate of DNA synthesis was only observed when IFN $\gamma$ was applied at the high dose of $100 \mathrm{ng} / \mathrm{ml}$, and combined with another stressor, the withdrawal of serum. To obtain a detectable STAT1 phosphorylation in DSL-6A/C1 cells, an IFN $\gamma$ concentration $\geq 10 \mathrm{ng} / \mathrm{ml}$ was required, while in cultured stellate cells $1 \mathrm{ng} / \mathrm{ml}$ was sufficient [10]. Furthermore, the activation profile of STAT1 in DSL-6A/C1 cells differed from the one previously observed in stellate cells in that a reduction of cytokine concentrations from 100 to $10 \mathrm{ng} / \mathrm{ml}$ was associated with a slower increase of phospho-STAT1 (Figure 8). As revealed by parameter value optimization of the mathematical model, a maximum of 1/500 of total STAT1 is located as phosphorylated STAT1 in the nucleus upon IFN $\gamma$ treatment of DSL-6A/C1 cells. Together, these results indicate that the cancer cells are less sensitive towards IFN $\gamma$ than pancreatic stellate cells, and suggest a less efficient activation of STAT1 signaling as a possible molecular explanation.

In the nude mouse model, it was found that PSCcontaining tumors grew faster and to larger volumes than pure DSL-6A/C1 tumors. This finding is in agreement with previous studies, which have revealed that co-injected PSC accelerate the growth of pancreatic cancer in animal models of the disease $[6,20,21]$. Moreover, the tumor stroma in pancreatic cancer has been shown to induce resistance of the tumor cells to drug treatment $[7,8,22]$. Possible mechanisms include paracrine effects of the stroma cells, an inefficient delivery of the antineoplastic agent to the tumor tissue, and a protection of the tumor against the immune system of the host (less relevant in the immunodeficient nude mouse model). In this context, it was interesting to note that IFN $\gamma$ inhibited the growth of tumors with and without stellate cells in a similar manner.

When grown in coculture, both PSC and DSL-6A/C1 cells proliferated at a higher rate than monocultures of the respective cell type, confirming previous results [14]. The antiproliferative effect of IFN $\gamma$ on both types of cells, however, remained significant, suggesting that its efficiency was not affected by the paracrine interactions between tumor and stellate cells. Molecular coupling factors between PSC and DSL-6A/C1 factors may include CTGF, TGF- $\beta 1$ and IL-6, all of which were found to be up-regulated in PSC upon coculture, and are known to be involved in PSC activation [5]. In the coculture model, IFN $\gamma$ increased expression of IL-1 $\beta$, which might favor the development of a pro-inflammatory microenvironment in the tumor.

The sensitivity of pure DSL-6A/C1 tumors towards IFN $\gamma$ treatment warrants further investigation. In pilot 


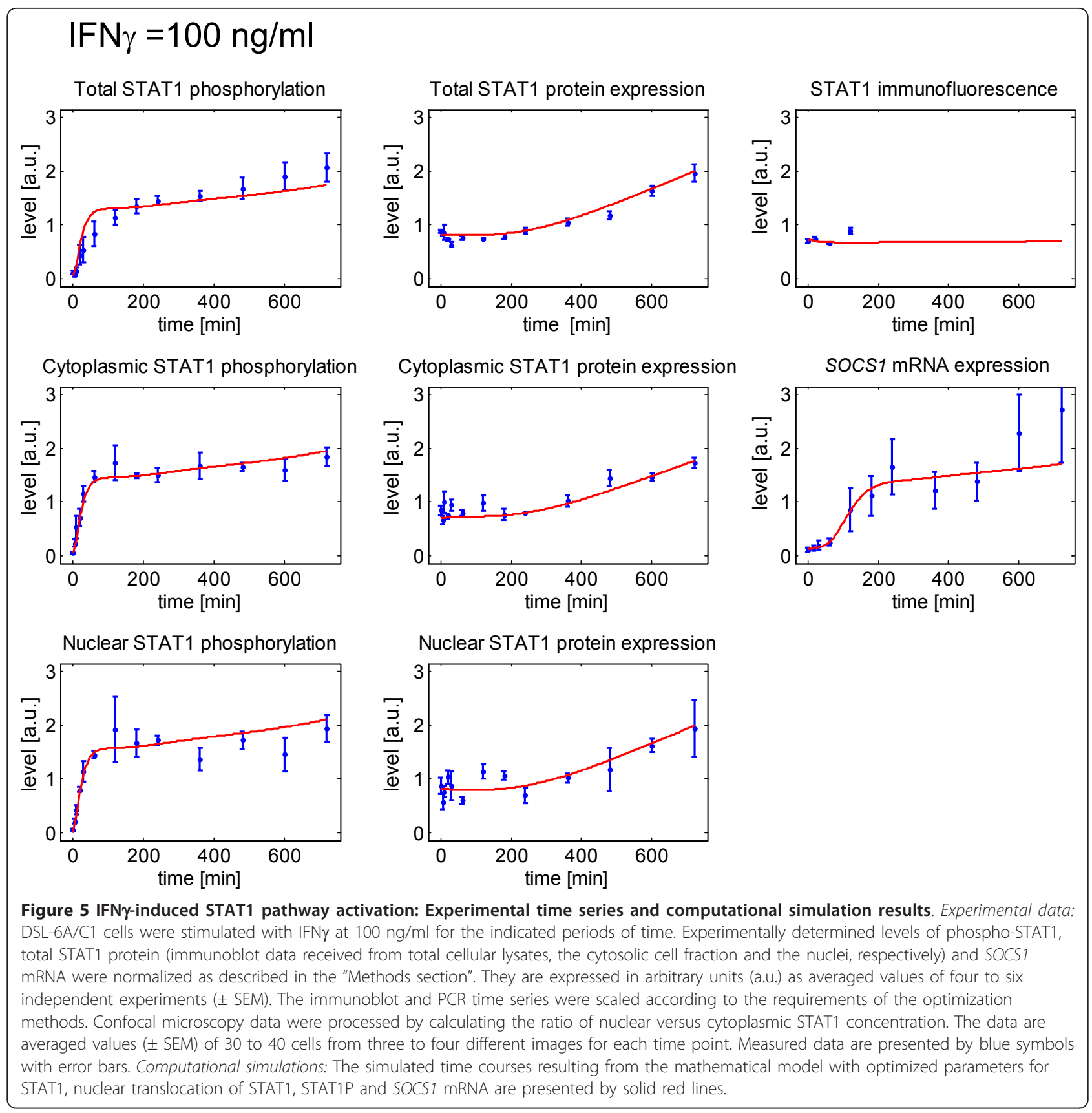

studies, we found that DSL-6A/C1 cells can attract local fibroblasts to the tumor, where they may exert effects of tumor stroma cells and are possibly targeted by IFN $\gamma$.

It has to be noted that the antitumor efficiency of IFN $\gamma$ may also depend on the differentiation status of the pancreatic cancer cells: IFN $\gamma$-responsive DSL-6A/C1 tumors are relatively well differentiated. Purely differentiated tumors of Panc02 cells [22], however, were found to be resistant to IFN $\gamma$ treatment when growing in C57Bl/6N mice (R. Jaster, unpublished data).

To this end, we have used the systems biology approach for the in vitro part of our experiments only.
Nevertheless, modeling and simulation proved helpful since it provided additional mechanistic insights into the action of IFN $\gamma$, which was the focus of this study. We are currently extending the effort to the simulation of experimental tumor growth in vivo. We believe that in the long run modeling may also become a valuable tool to monitor and predict the efficiency of antineoplastic agents. A major challenge on this way is the lack of quantitative and kinetic data of high density and quality, appropriate for data-driven modeling in which parameter values of kinetic (dynamical) models are directly estimated from time course data. 


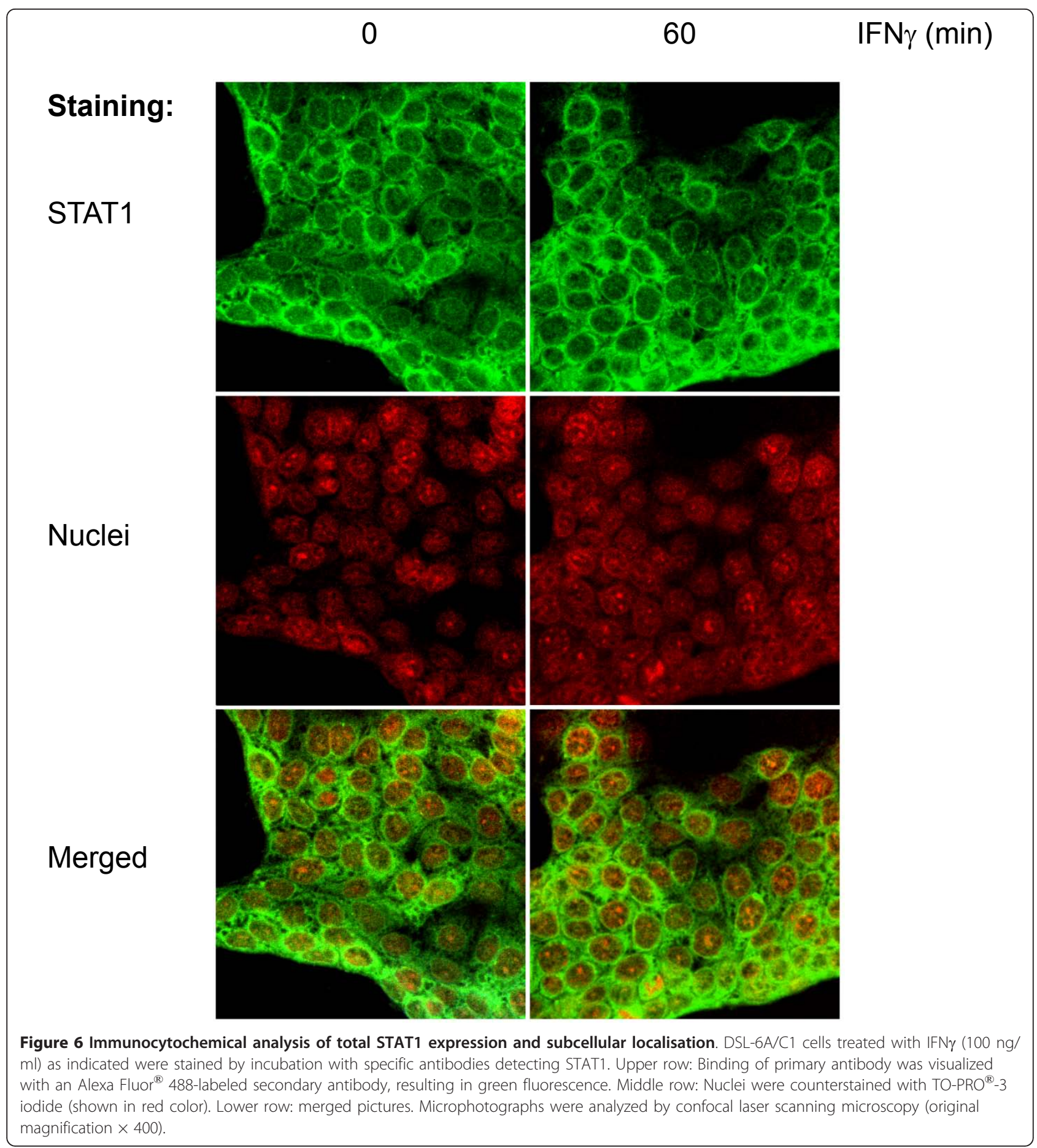

\section{Conclusions}

In a heterotopic nude mouse model of pancreatic cancer, IFN $\gamma$ significantly inhibited the growth of tumors containing co-transplanted stellate cells, which accelerated tumor progression. On pure DSL-6A/C1 tumors, IFN $\gamma$ displayed a quantitatively similar but statistically not significant growth inhibitory effect. PSC are more sensitive to the antiproliferative action of IFN $\gamma$ than DSL-6A/C1 pancreatic cancer cells. A possible explanation is provided by our experimental data and computer simulations, since they concordantly indicate that in DSL-6A/ $\mathrm{C} 1$ cells only a small fraction of the key transcription factor STAT1 is located as phosphorylated protein in the nucleus upon IFN $\gamma$ stimulation. We therefore hypothesize 


\section{IFN $\gamma=10 \mathrm{ng} / \mathrm{ml}$}

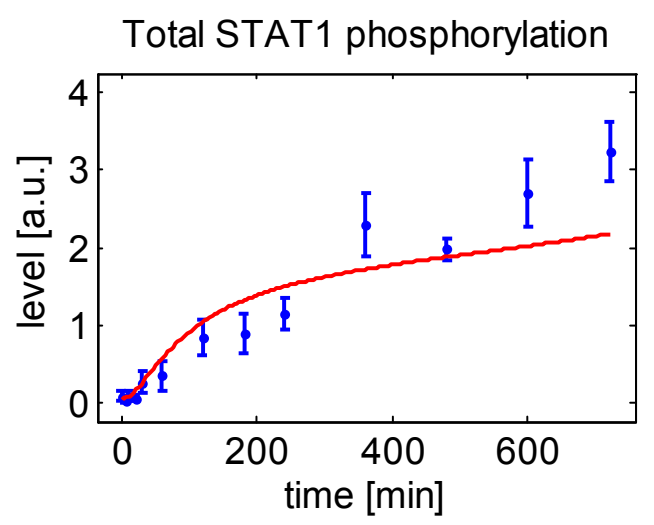

\section{Total STAT1 protein expression}

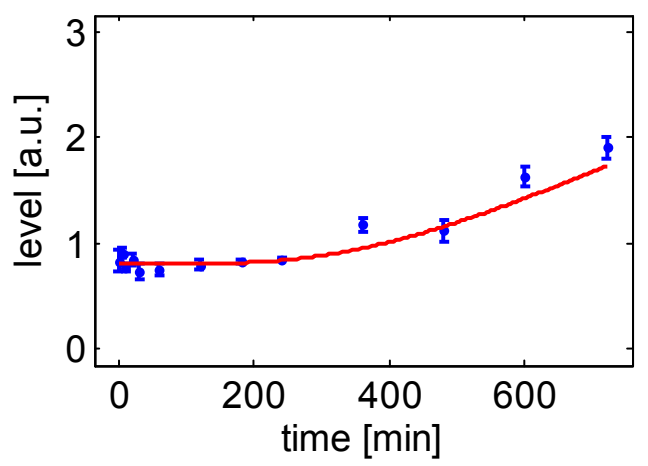

Figure 7 Effects of IFN $\gamma$ at $10 \mathrm{ng} / \mathrm{ml}$ on STAT1 protein expression and phosphorylation. Experimental data: DSL-6A/C1 cells were stimulated with IFN $\gamma$ for the indicated periods of time. Phospho-STAT1 and STAT1 protein levels in total cellular lysates were determined by immunoblot analysis. The data were processed as described in the legend to Fig. 5. Averaged values ( \pm SEM) of four independent experiments are presented by blue symbols. Computational simulations: The simulated time courses resulting from the mathematical model are presented by solid red lines.

that the antiproliferative effect of IFN $\gamma$ on pure DSL-6A/ $\mathrm{C} 1$ tumors is mediated, at least in part, by the targeting of additional cell types, such as local fibroblasts.

\section{Methods \\ Materials}

Iscove's modified Dulbecco's medium (IMDM), Dulbecco's Modified Eagle Medium (DMEM) and supplements for cell culture were obtained from Biochrom (Berlin, Germany), recombinant rat IFN $\gamma$ from Immunotools (Friesoythe, Germany), and bovine serum albumin (BSA) from Roche Diagnostics (Mannheim, Germany). TriReagent ${ }^{\circledR}$ was purchased from Ambion (Austin, TX, USA). Reverse transcription and Taqman $^{\text {TM }}$ reagents were delivered by Applied Biosystems (Foster City, CA, USA). Primary antibodies were from
BD Biosciences (Franklin Lakes, NJ, USA; anti-pY701STAT1; mouse monoclonal), Upstate Cell Signaling Solutions (Billerica, MA, USA; anti-extracellular signalregulated kinase (ERK) 1/2; rabbit polyclonal), Santa Cruz (Santa Cruz, CA, USA; anti-STAT1; rabbit polyclonal) and New England BioLabs (Frankfurt, Germany; anti-GAPDH; rabbit monoclonal and anti-lamin A/C; rabbit polyclonal). Fluorescently-labeled secondary antibodies for immunoblot analysis and Odyssey ${ }^{\circledR}$ blocking buffer were supplied by LI-COR (Lincoln, NE, USA). Polyvinylidene fluoride (PVDF) membrane was from Millipore (Billerica, MA, USA), and TO-PRO ${ }^{\circledR}-3$ iodide as well as Alexa Fluor ${ }^{\circledR}$ reagents from Invitrogen (Darmstadt, Germany). Tissue culture dishes (corning plasticware) and all other chemicals were from Sigma (Deisenhofen, Germany).

\section{Cell culture}

Stellate cells from rat pancreas were isolated by collagenase digestion of the organ followed by Nycodenz density gradient centrifugation as previously described [23], and cultured in IMDM supplemented with $17 \%$ fetal calf serum (FCS), 1\% non-essential amino acids (dilution of a $100 \times$ stock solution), $100 \mathrm{U} / \mathrm{ml}$ penicillin and $100 \mu \mathrm{g} / \mathrm{ml}$ streptomycin. PSC were harvested by trypsinization on day seven after isolation and recultured at equal seeding densities according to the experimental requirements. All experiments were performed with cells passaged no more than 2 times. The rat pancreas carcinoma cell line DSL-6A/C1 was obtained from American Type Culture Collection (ATCC), and cultured in DMEM supplemented with 10\% FCS and antibiotics (100 U/ml penicillin; $100 \mu \mathrm{g} / \mathrm{ml}$ streptomycin).

Coculture studies were performed in 24-transwell plates using inserts with a pore size of $0.4 \mu \mathrm{m}$. Therefore, DSL-6A/C1 cells and PSC were seeded into the upper or lower chamber of separate transwells, respectively. After an overnight incubation, culture medium was replenished, transwell chambers were assembled by transferring the inserts, and IFN $\gamma$ was added according to the experimental design. All cells were grown at $37^{\circ} \mathrm{C}$ in a $5 \% \mathrm{CO}_{2}$ humidified atmosphere.

\section{Animal tumor model and IFN $\gamma$ treatment}

$\mathrm{BALB} / \mathrm{c}-n u / n u$ mice were purchased from Charles River Laboratories (Sulzfeld, Germany), kept under standard laboratory conditions and fed a rodent chow diet. All experiments were performed according to the guidelines of the local animal use and care committee.

Three month old male mice were injected subcutaneously into the left hind flank with $1 \times 10^{6} \mathrm{DSL}-6 \mathrm{~A} / \mathrm{C} 1$ cells, and a mixture of $1 \times 10^{6} \mathrm{DSL}-6 \mathrm{~A} / \mathrm{C} 1$ cells $/ 1 \times 10^{6}$ PSC into the opposite site. Over the entire period of investigation, tumor growth was monitored twice a 


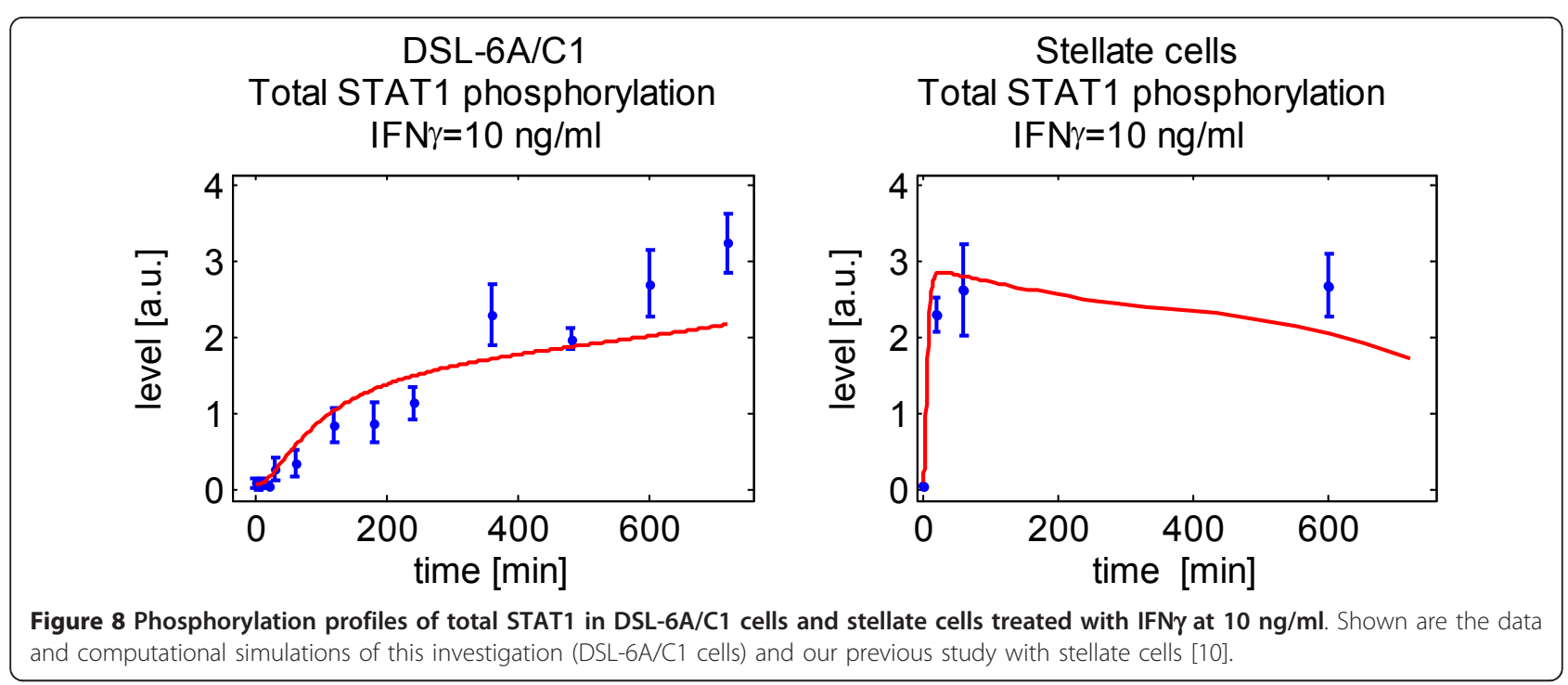

week, and volumes of outgrowing tumors were evaluated according to the following formula: width ${ }^{2} \times$ length $\times$ 0.52 [24]. Treatment was initiated when the fastergrowing tumor had reached a size of $6 \mathrm{~mm}$ in one dimension (defined as day 0 ). Therefore, the mice were randomized into two groups, and treated with IFN $\gamma$ (intraperitoneal injections of $10 \mu \mathrm{g}$ per day, $\mathrm{n}=4$ ), or solvent only (controls; $\mathrm{n}=6$ ) for 28 days. Afterwards, the animals were sacrificed, and tumors from both flanks removed for further analysis.

\section{Cell proliferation assay}

To assess proliferation of cells growing alone or in coculture, incorporation of 5-bromo-2'-deoxyuridine (BrdU) into newly synthesized DNA was quantified using the BrdU labeling and detection enzyme-linked immunosorbent assay kit (Roche Diagnostics). Therefore, the cells were incubated with IFN $\gamma$ and BrdU as indicated, and BrdU uptake of cells growing in the lower chamber (PSC and DSL-6A/C1 cells, respectively) was measured according to the manufacturer's instructions. In studies with monocultures of DSL-6A/C1 or PSC, transwell inserts were omitted. For each experimental regime (coculture studies, dose-response experiments and studies on the effects of FCS), the times of IFN $\gamma$ treatment were optimized in pilot investigations.

\section{Immunoblotting}

To receive unfractionated total cellular protein, boiling lysis buffer ( $2 \%$ sodium dodecyl sulphate [SDS], 10\% glycerol, $5 \mathrm{mM}$ ethylenediaminetetraacetic acid [pH 8.0], 62.5 mM Tris- $\mathrm{HCl}$ [pH 6.8], 0.01\% 3,3',5,5'-tetrabromophenolsulfonphthalein, $5 \% \beta$-mercaptoethanol) was added directly to the cell monolayer. Nuclear extracts and the cytosolic fraction of the cells were prepared using the ProteoJET ${ }^{\mathrm{TM}}$ cytoplasmic and nuclear protein extraction kit (Fermentas, St. Leon-Rot, Germany) according to the instructions of the manufacturer.

Cellular proteins received from equal numbers of cells were separated by $8 \%$ SDS-polyacrylamide gel electrophoresis and blotted onto PVDF membrane. Afterwards, membranes were blocked for one hour using Odyssey ${ }^{\circledR}$ blocking buffer, before primary antibodies were added and incubation continued for another hour. Simultaneous detection of tyrosine-phosphorylated STAT1 and total STAT1 was performed as previously described [10]. Expression of ERK 1/2, GAPDH and lamin A/C was investigated by adding specific antibodies separately to the lower part of the membrane. IRDye ${ }^{\circledR} 800 \mathrm{CW}$ and IRDye $^{\circledR} 680 \mathrm{CW}$ conjugated secondary antibodies were applied for detection of primary antibody binding.

Using an Odyssey ${ }^{\circledR}$ Infrared Imaging System, all immunoblots were scanned at a wavelength of $700 \mathrm{~nm}$ for detecting IRDye ${ }^{\circledR} 680$ labeled antibodies and at a wavelength of $800 \mathrm{~nm}$ for IRDye ${ }^{\circledR} 800 \mathrm{CW}$ conjugated antibodies. Signal intensities were quantified by means of the Odyssey ${ }^{\circledR}$ software version 3.16. Signals obtained for phosphorylated STAT1 and total STAT1 protein were normalized for loading differences by calculating the ratio of phospho-STAT1 (or STAT1) to ERK 1/2 (total cellular protein), GAPDH (cytosolic fraction) and lamin A/C (nuclear extracts). Under the experimental conditions used in this study, protein levels of ERK 1/2, GAPDH and lamin A/C in the cells remained constant (data not shown). In a second step each time series was normalized to its average value over time. Finally the average value of four to six experiments was calculated for each time point. 


\section{Confocal microscopy}

DSL-6A/C1 cells were cultured on coverslips. After stimulation with IFN $\gamma$, the cells were fixed in methanol at $-20^{\circ} \mathrm{C}$ for $10 \mathrm{~min}$ and washed twice with TBS $(20 \mathrm{mM}$ Tris, $150 \mathrm{mM} \mathrm{NaCl}, \mathrm{pH}$ 7.6; supplemented with $0.5 \%$ BSA, $0.05 \%$ Tween 20). Nonspecific binding sites were blocked with Roti ${ }^{\circledR}$-ImmunoBlock solution (Carl Roth, Karlsruhe, Germany). Afterwards, the fixed cells were incubated with anti-STAT1 (in Roti ${ }^{\circledR}$-ImmunoBlock solution) overnight at $4^{\circ} \mathrm{C}$. After washing with TBS, the coverslips were stained with Alexa Fluor ${ }^{\circledR} 488$ goat antirabbit IgG. Subsequently, the cells were washed and nuclei were stained with TO-PRO ${ }^{\circledR}-3$ iodide. Finally, the cells were fixed with $2 \%$ paraformaldehyde for $15 \mathrm{~min}$ and embedded in mounting medium (25\% glycerol, $10 \%$ polyvinylalcohol, $0.4 \%$ phenol, $0.05 \mathrm{M}$ Tris, $\mathrm{pH} 8.5$ ) on microscope slides. Fluorescence analysis was performed by using a confocal laser scanning microscope LSM 5 Pascal (Axiovert $200 \mathrm{M}$ ) and Zen 2007 (4.5) software (Carl-Zeiss, Jena, Germany). Images were further analyzed using the ImageJ (Open Source software package). To quantify nuclear translocation of STAT1, averaged ratios of nuclear versus cytoplasmic concentration (sum of pixel intensity divided by area) of STAT1 were calculated. Therefore, 30 to 40 cells from three to four different images were analyzed for each time point.

\section{Quantitative reverse transcriptase-PCR using real-time TaqMan $^{\text {TM }}$ technology}

DSL-6A/C1 cells and PSC, growing in FCS-containing culture medium, were treated with IFN $\gamma$ as indicated, and total RNA was isolated with TriReagent ${ }^{\circledR}$ according to the manufacturer's instructions. Subsequently, RNA was reverse transcribed into cDNA by means of TaqMan ${ }^{\mathrm{TM}}$ Reverse Transcription Reagents and random hexamer priming. Target cDNA levels were analyzed by quantitative real-time PCR using TaqMan ${ }^{\mathrm{TM}}$ Universal PCR Master Mix and the following Assay-on-Demand ${ }^{\mathrm{TM}}$ rat gene-specific fluorescently labelled TaqMan ${ }^{\mathrm{TM}} \mathrm{MGB}$ probes in an ABI Prism 7000 sequence detection system (Applied Biosystems): Rn00595838_s1 (SOCS1), Rn00573960_g1 (CTGF), Rn00580432_m1 (IL-1ß), Rn00561420_m1 (IL-6), Rn00572010_m1 (TGF- $\beta 1)$ and Rn01527840_m1 (hypoxanthine-guanine phosphoribosyl transferase [HPRT]). PCR was started with an initial denaturation at $95^{\circ} \mathrm{C}$ for $10 \mathrm{~min}$, followed by 55 cycles of $15 \mathrm{~s}$ at $95^{\circ} \mathrm{C}$ and $1 \mathrm{~min}$ at $60^{\circ} \mathrm{C}$. The relative expression of each mRNA compared with HPRT was calculated according to the equation $\Delta \mathrm{Ct}=\mathrm{Ct}_{\text {target }}-\mathrm{Ct}_{\mathrm{HPRT}}$. After averaging over at least two technical replicates, the amount of target mRNA was expressed as $2^{-(\Delta C t)}$. In case of time course experiments, the time series of $2^{-(\Delta \mathrm{Ct})}$ was normalized to its average value over time. Finally, the averaged value of the indicated number of experiments was calculated for each time point.

\section{Mathematical model}

The reaction network (Figure 3), describing IFN $\gamma$ signaling in DSL-6A/C1, was translated into a system of ODEs which describe temporal changes of the network components as a function of interactions and transport processes. The model is presented in the Additional file 1.

The kinetic model is based on the following assumptions and simplifications: (a) There is no IFN $\gamma$ degradation. (b) IFN $\gamma$ activates Ir and the active receptor IIr phosphorylates STAT1U. (c) The formation of STAT1 $\mathrm{D}$ is a rapid and high affinity process $[25,26]$. (d) Nucleo-cytoplasmic shuttling is modeled as a free diffusion process. (e) The quantification of the confocal microscopy data led to the result that the cytoplasmic area occupied by STAT1 has the same size as the nuclear area (data not shown). (f) Our model includes a reversible binding of STAT1 D to DNA, which determines the resting of STAT1 D in the nucleus [27], (g) Only free nuclear STAT1 D can be dephosphorylated and dissociate into monomers, leading to nuclear STAT1U [26]. (h) Feedback inhibition by SOCS1 may reduce STAT1U phosphorylation $[28,29]$. (i) The delayed processes of increased STAT1U expression, SOCS1 transcription and the negative feedback by SOCS1 are described by a distributed time delay with mean delay times $\bar{\tau}_{i}$ [30]. The model assumptions are the same as for our model in PSC except of (a) and (b). For further details regarding the assumptions see [10].

\section{Parameter value estimation}

The parameters of the model whose values need to be estimated include reaction constants, delay times, immunoblot scaling factors and initial conditions of some model variables. Their values are estimated by global optimization from protein and mRNA time series for low concentrations $(10 \mathrm{ng} / \mathrm{ml})$ and higher concentrations $(100 \mathrm{ng} / \mathrm{ml})$ of IFN $\gamma$. For estimation we have used a hybrid approach combined of a stochastic simulated annealing algorithm performing a global search and a deterministic trust region algorithm performing a local search. The hybrid approach is implemented in the routine pwFitBoost of the MATLAB toolbox PottersWheel [31]. Results from parameter value estimation are presented in the Additional files 2 and 3.

\section{Statistical analysis}

Results are expressed as means \pm standard error of the mean (SEM) for the indicated number of animals or independent cultures per experimental protocol. Statistical significance was determined using tests as specified 
in the figure legends and where $\mathrm{p}<0.05$ was considered as statistically significant.

\section{Additional material}

Additional file 1: Mathematical model describing the reactions of the network in Figure 3. The reaction network was translated into a system of ordinary differential equations (ODE), which describes temporal changes of the network components as a function of interactions and transport processes. The ODE model is shown in the upper part of Additional file 1. The abbreviation S stands for STAT1. The variables of the model representing cellular components are concentrations but their units are arbitrary due to the lack of standard curves. The initial conditions of IIr, STAT1Dn and STAT1Dnd were set to zero. They are summarized below the ODE. The initial condition of a variable refers to its value at time point zero and is annotated by (0) after its name. The total concentration of STAT1 and the total IFN $\gamma$ receptor concentration I are redundant parameters. We have fixed I as 1/10 of initial experimental STAT1. The initial value of STAT1 results from the optimization of the initial values of STAT1DC, STAT1Uc and STAT1Un. The algebraic equations in the lower part of Additional file 1 relate the model variables to the experimental data. Immunoblot data can be scaled by arbitrary factors. We have chosen different scaling factors for STAT1C, STAT1n, STAT1 D, STAT1DC, STAT1Dn, annotated by "WB" with the respective form of the protein in the subscript. Scaling factors for STAT1 and SOCS1 mRNA have not been included because scaled variables inserted in the model show that the respective scaling factors are redundant parameters. In addition, the ratio of nuclear versus cytoplasmic concentration of STAT1 (RSNC) has been calculated from the confocal microscopy data.

Additional file 2: Estimation of parameter values. ${ }^{\text {a }}$ While global parameters are independent of the IFN $\gamma$ concentration, local parameters depend on it. a.u. = arbitrary units. The parameters of the mathematical model include reaction constants and delay times. The parameter values were estimated by global optimization from the protein and mRNA time series. We have used a hybrid algorithm composed of simulated annealing and a local search implemented in the MATLAB toolbox PottersWheel [1]. As a measure for the goodness of how a simulation of the model reproduces experimental data, the following cost function was applied:

$$
\chi^{2}(\theta)=\sum_{k=1}^{m} \sum_{l=1}^{d}\left(\frac{y_{k l}^{\exp }-y_{k}^{\bmod }}{\sigma_{k l}^{\exp }}\right)^{2}
$$

where $\theta$ is the parameter vector, $y_{k l}^{\exp }$ are the experimental data, $y_{k}^{\text {mod }}$ values of observables at time points of the experimental data $\sigma_{k l}^{\exp }$ and is the measurement error of the experimental data [1].References 1. Maiwald T, Timmer J: Dynamical modeling and multi-experiment fitting with PottersWheel. Bioinformatics 2008, 24:2037-2043.

\section{Additional file 3: Cost function for different fixed relative} concentrations of STAT1Dn for IFN $\gamma=100 \mathrm{ng} / \mathrm{ml}$. To estimate an upper boundary for the relative concentration of nuclear STAT1Dn, we fixed the scaling factor WBSTATIDn at different increasing values and reoptimized the other parameter values. The respective values of the cost function are summarized in the left part of the table. For WBSTAT1Dn $=$ 1000 the cost function reaches a plateau. In the right part of the table the maximal relative concentration of STAT1Dn is calculated from this value. For $\mathrm{t}=180 \mathrm{~min}$ the concentration of STAT1Dn is $1 / 500$ of the STAT1 concentration and for $\mathrm{t}=720$ min the concentration of STAT1Dn is $1 / 1000$ of STAT1 concentration.

\section{List of Abbreviations}

a.u.: arbitrary unit; ATCC: American Type Culture Collection; BrdU: 5-bromo2'-deoxyuridine; BSA: bovine serum albumine; CTGF: connective tissue growth factor; DMEM: Dulbecco's Modified Eagle Medium; ERK: extracellular signal-regulated kinase; FCS: fetal calf serum; HPRT: hypoxanthine-guanine phosphoribosyl transferase; IFN: interferon; IMDM: Iscove's modified Dulbecco's medium; IIr: active IFNY receptor; IL: Interleukin; Ir: inactive IFNY receptor; PC: pancreatic cancer; PSC: pancreatic stellate cell; PVDF: polivinylidene fluoride; ODE: ordinary differential equation; RSNC: ratio of nuclear versus cytoplasmic concentration of STAT1; SDS: sodium dodecyl sulphate; SEM: standard error of the mean; SOCS: suppressor of cytokine signaling; STAT: signal transducer and activator of transcription; STAT1P: phosphorylated (Phospho-) STAT1; STAT1c: STAT1 in the cytoplasm; STAT1n: STAT1 in the nucleus; STAT1D: phosphorylated STAT1 dimer; STAT1DC: phosphorylated STAT1 dimer in the cytoplasm; STAT1Dn: phosphorylated STAT1 dimer in the nucleus; STAT1Dnd: phosphorylated STAT1 dimer bound to DNA; STAT1U: unphosphorylated STAT1; STAT1Uc: unphosphorylated STAT1 in the cytoplasm; STAT1Un: unphosphorylated STAT1 in the nucleus; TBS: tris-buffered saline; TGF- $\beta$ 1: transforming growth factor- $\beta 1$

\section{Acknowledgements}

We gratefully acknowledge the excellent technical assistance of Mrs. Katja Bergmann, and thank Mrs. Christina Kossow for critical reading of the manuscript. This work was supported by grants from the Bundesministerium für Bildung und Forschung through the FORSYS partner program (grant number 0315255 to KR) and the Deutsche Forschungsgemeinschaft (to RJ). OW acknowledges support from the Helmholtz Society as part of the systems biology network.

\section{Author details}

'Department of Systems Biology and Bioinformatics, University of Rostock, 18051 Rostock, Germany. ${ }^{2}$ Department of Medicine II, Division of Gastroenterology, Medical Faculty, University of Rostock, 18057 Rostock, Germany. ${ }^{3}$ Unit of Reproductive Biology, Leibniz Institute for Farm Animal Biology, Wilhelm-Stahl-Allee 2, 18196 Dummerstorf, Germany.

\section{Authors' contributions}

$\mathrm{FL}$ and $\mathrm{BF}$ participated in performing the experiments, data analysis and interpretation of the results. KR established the mathematical model and was involved in the design of the experiments, data analysis and writing of the paper. RP performed the confocal microscopy studies. OW and RJ conceived the study and participated in data analysis and interpretation of the results. RJ also conducted the in vivo experiments and wrote the manuscript. All authors have read and approved the final manuscript.

\section{Competing interests}

The authors declare that they have no competing interests.

Received: 16 August 2010 Accepted: 10 February 2011 Published: 10 February 2011

\section{References}

1. Wolkenhauer O, Auffray C, Baltrusch S, Blüthgen N, Byrne H, Cascante M, Ciliberto A, Dale T, Drasdo D, Fell D, Ferrell JE Jr, Gallahan D, Gatenby R, Günther U, Harms BD, Herzel H, Junghanss C, Kunz $M$, van Leeuwen I, Lenormand P, Levi F, Linnebacher $M$, Lowengrub J, Maini PK, Malik A, Rateitschak K, Sansom O, Schäfer R, Schürrle K, Sers C, Schnell S, Shibata D, Tyson J, Vera J, White M, Zhivotovsky B, Jaster R: Systems biologists seek fuller integration of systems biology approaches in new cancer research programs. Cancer Res 2010, 70:12-13.

2. Eckel F, Schneider G, Schmid RM: Pancreatic cancer: a review of recent advances. Expert Opin Investig Drugs 2006, 15:1395-1410.

3. Schneider G, Siveke JT, Eckel F, Schmid RM: Pancreatic cancer: basic and clinical aspects. Gastroenterology 2005, 128:1606-1625.

4. Apte MV, Park S, Phillips PA, Santucci N, Goldstein D, Kumar RK, Ramm GA, Buchler M, Friess H, McCarroll JA, Keogh G, Merrett N, Pirola R, Wilson JS: Desmoplastic reaction in pancreatic cancer: role of pancreatic stellate cells. Pancreas 2004, 29:179-187.

5. Jaster R, Emmrich J: Crucial role of fibrogenesis in pancreatic diseases. Best Pract Res Clin Gastroenterol 2008, 22:17-29.

6. Bachem MG, Schunemann M, Ramadani M, Siech M, Beger H, Buck A, Zhou S, Schmid-Kotsas A, Adler G: Pancreatic carcinoma cells induce fibrosis by stimulating proliferation and matrix synthesis of stellate cells. Gastroenterology 2005, 128:907-921. 
7. Müerköster S, Wegehenkel K, Arlt A, Witt M, Sipos B, Kruse ML, Sebens T, Klöppel G, Kalthoff H, Fölsch UR, Schäfer H: Tumor stroma interactions induce chemoresistance in pancreatic ductal carcinoma cells involving increased secretion and paracrine effects of nitric oxide and interleukin1beta. Cancer Res 2004, 64:1331-1337.

8. Miyamoto H, Murakami T, Tsuchida K, Sugino H, Miyake H, Tashiro S: Tumor-stroma interaction of human pancreatic cancer: acquired resistance to anticancer drugs and proliferation regulation is dependent on extracellular matrix proteins. Pancreas 2004, 28:38-44.

9. Baumert JT, Sparmann G, Emmrich J, Liebe S, Jaster R: Inhibitory effects of interferons on pancreatic stellate cell activation. World J Gastroenterol 2006, 12:896-901.

10. Rateitschak K, Karger A, Fitzner B, Lange F, Wolkenhauer O, Jaster R: Mathematical modelling of interferon- $\gamma$ signalling in pancreatic stellate cells reflects and predicts dynamics of STAT1 pathway activity. Cell Signal 2010, 22:97-105.

11. Stark GR, Kerr IM, Williams BRG, Silverman RH, Schreiber RD: How cells respond to interferons. Annu Rev Biochem 1998, 67:227-264.

12. Nukui Y, Picozzi VJ, Traverso LW: Interferon-based adjuvant chemoradiation therapy improves survival after pancreaticoduodenectomy for pancreatic adenocarcinoma. Am J Surg 2000, 179:367-371.

13. Picozzi VJ, Kozarek RA, Traverso LW: Interferon-based adjuvant chemoradiation therapy after pancreaticoduodenectomy for pancreatic adenocarcinoma. Am J Surg 2003, 185:476-480.

14. Fitzner B, Brock P, Holzhüter SA, Nizze H, Sparmann G, Emmrich J, Liebe $S$, Jaster R: Synergistic growth inhibitory effects of the dual endothelin-1 receptor antagonist bosentan on pancreatic stellate and cancer cells. Dig Dis Sci 2009, 54:309-320.

15. Jeong WI, Park O, Gao B: Abrogation of the antifibrotic effects of natural killer cells/interferon-gamma contributes to alcohol acceleration of liver fibrosis. Gastroenterology 2008, 134:248-258.

16. Bouros D, Antoniou KM, Tzouvelekis A, Siafakas NM: Interferon-gamma 1b for the treatment of idiopathic pulmonary fibrosis. Expert Opin Biol Ther 2006, 6:1051-1060.

17. Meraz MA, White JM, Sheehan KC, Bach EA, Rodig SJ, Dighe AS, Kaplan DH, Riley JK, Greenlund AC, Campbell D, Carver-Moore K, DuBois RN, Clark R, Aguet M, Schreiber RD: Targeted disruption of the Stat1 gene in mice reveals unexpected physiologic specificity in the JAK-STAT signaling pathway. Cell 1996, 84:431-442.

18. Durbin JE, Hackenmiller R, Simon MC, Levy DE: Targeted disruption of the mouse Stat 1 gene results in compromised innate immunity to viral disease. Cell 1996, 84:443-450.

19. Fitzner B, Brock P, Nechutova H, Glass A, Karopka T, Koczan D, Thiesen HJ, Sparmann G, Emmrich J, Liebe S, Jaster R: Inhibitory effects of interferongamma on activation of rat pancreatic stellate cells are mediated by STAT1 and involve down-regulation of CTGF expression. Cell Signal 2007, 19:782-790.

20. Vonlaufen A, Joshi S, Qu C, Phillips PA, Xu Z, Parker NR, Toi CS, Pirola RC, Wilson JS, Goldstein D, Apte MV: Pancreatic stellate cells: partners in crime with pancreatic cancer cells. Cancer Res 2008, 68:2085-2093.

21. Hwang RF, Moore T, Arumugam T, Ramachandran V, Amos KD, Rivera A Ji B, Evans DB, Logsdon CD: Cancer-associated stromal fibroblasts promote pancreatic tumor progression. Cancer Res 2008, 68:918-926.

22. Corbett TH, Roberts BJ, Leopold WR, Peckham JC, Wilkoff LJ, Griswold DP Jr, Schabel FM Jr: Induction and chemotherapeutic response of two transplantable ductal adenocarcinomas of the pancreas in C57BL/6 mice. Cancer Res 1984, 4:717-726.

23. Jaster R, Sparmann G, Emmrich J, Liebe S: Extracellular signal-regulated kinases are key mediators of mitogenic signals in rat pancreatic stellate cells. Gut 2002, 51:579-584.

24. Agrawal N, Bettegowda C, Cheong I, Geschwind JF, Drake CG, Hipkiss EL, Tatsumi M, Dang LH, Diaz LA Jr, Pomper M, Abusedera M, Wahl RL, Kinzler KW, Zhou S, Huso DL, Vogelstein B: Bacteriolytic therapy can generate a potent immune response against experimental tumors. ProC Natl Acad Sci USA 2004, 101:15172-15177.

25. Levy DE, Darnell JE Jr: Stats: transcriptional control and biological impact. Nat Rev Mol Cell Biol 2002, 3:651-662.

26. Beirer S: Mathematical modelling of the Jak/Stat1 signal transduction pathway Berlin: Logos Verlag Berlin GmbH; 2007.
27. Begitt $A$, Meyer $T$, van Rossum M, Vinkemeier U: Nucleocytoplasmic translocation of Stat1 is regulated by a leucine-rich export signal in the coiled-coil domain. Proc Natl Acad Sci USA 2000, 97:10418-10423.

28. Wormald S, Zhang JG, Krebs DL, Mielke LA, Silver J, Alexander WS, Speed TP, Nicola NA, Hilton DJ: The comparative roles of suppressor of cytokine signaling- 1 and -3 in the inhibition and desensitization of cytokine signaling. J Biol Chem 2006, 281:11135-11143.

29. Endo TA, Masuhara M, Yokouchi M, Suzuki R, Sakamoto H, Mitsui K, Matsumoto A, Tanimura S, Ohtsubo M, Misawa H, Miyazaki T, Leonor N, Taniguchi T, Fujita T, Kanakura Y, Komiya S, Yoshimura A: A new protein containing an SH2 domain that inhibits JAK kinases. Nature 1997, 387:921-924

30. MacDonald N: Biological delay systems: linear stability theory Cambridge: Cambridge University Press; 2003.

31. Maiwald T, Timmer J: Dynamical Modeling and multi-experiment fitting with PottersWheel. Bioinformatics 2008, 24:2037-2043.

32. Yang J, Stark GR: Roles of unphosphorylated STATs in signalling. Cell Res 2008, 18:443-451.

33. Schilling M, Maiwald T, Bohl S, Kollmann M, Kreutz C, Timmer J, Klingmüller U: Computational processing and error reduction strategies for standardized quantitative data in biological networks. FEBS J 2005, 272:6400-6411.

doi:10.1186/1476-4598-10-13

Cite this article as: Lange et al:: Studies on mechanisms of interferongamma action in pancreatic cancer using a data-driven and modelbased approach. Molecular Cancer 2011 10:13.

\section{Submit your next manuscript to BioMed Central and take full advantage of:}

- Convenient online submission

- Thorough peer review

- No space constraints or color figure charges

- Immediate publication on acceptance

- Inclusion in PubMed, CAS, Scopus and Google Scholar

- Research which is freely available for redistribution 